\title{
Leuven Kemoterapi Hasta Bilgi Ölçeğinin Türkçe Geçerlik ve Güvenirliğinin Değerlendirilmesi $\infty$
}

\author{
Serpil SU ${ }^{1}$, Şule ECEVIT ALPAR ${ }^{2}$
}

Öz

Amaç: Araştırma, Leuven Kemoterapi Hasta Bilgi Ölçeği (LKHBÖ)'nin geçerlik ve güvenirliğini değerlendirmek amacıyla gerçekleştirildi.

Gereç ve Yöntem: Metodolojik tipte olan araştırmanın evrenini Konya ilindeki iki hastanenin ayaktan kemoterapi ünitelerinde kemoterapi uygulanan tüm hastalar, örneklemini ise Mart-Temmuz 2014 tarihleri arasında kemoterapi tedavisi uygulanan 239 hasta oluşturdu. Araştırmanın verileri Hasta Bilgi Formu, L-KHBÖ kullanılarak toplandı.

Bulgular: L-KHBÖ'nin geçerlik-güvenirlik çalışması doğrultusunda Cronbach Alpha'sı 0.86; maddelerin toplam puan korelasyonu $\mathrm{rs}=0.25$ ile 0.58 arasında; uyum indeksleri Ki-kare:151.83 ( $p \leq 0.001$ ), Serbestlik Derecesi:100. RMSEA:0.047, SRMR:0.061, CFI:0.90, NNFI:0.88, GFI:0.93, AGFI: 0.90 olarak; test ve tekrar test korelasyonu $\mathrm{r}: 0.71, p \leq 0.001$ olarak bulundu.

Sonuç: L-KHBÖ’nin Türkçe formunun geçerli ve güvenilir bir ölçek olduğu belirlendi.

Anahtar kelimeler: Bilgi düzeyi, geçerlik, güvenirlik, kemoterapi

\begin{abstract}
Reliability and Validity Assessment of the Turkish Version of the Leuven Questionnaire on Patient Knowledge of Chemotherapy

Aim: The research was conducted in order to evaluate the validity and reliability of the Leuven Questionnaire on Patient Knowledge of Chemotherapy (L-PaKC).

Material and Methods: The population of the study, which is a methodological type, consisted of all patients who received chemotherapy in outpatient chemotherapy units of two hospitals in Konya, and the sample consisted of 239 patients who received chemotherapy between March and July 2014. The data of the study were collected using Patient Information Form, L-PaKC and analyzed using the SPSS 20.0 package program.

Results: As a result of the validity-reliability study of L-PaKC, Cronbach Alpha was 0.86 , the total score correlation of the items was between rs:0.25 and 0.58, fit index was Chi-Square: 151.83 $(p \leq 0.001)$, Degrees of Freedom:100, RMSEA:0.047, SRMR:0.061, CFI:0.90, NNFI:0.88, GFI:0.93, AGFI:0.90, and test and re-test correlation was found as $\mathrm{r}: 0.71, \mathrm{p} \leq 0.001$.

Conclusion: : It was determined that the Turkish version of L-PaKC is a valid and reliable scale.

Keywords: Chemotherapy, level of knowledge, reliability, validity
\end{abstract}

1Dr. Öğr. Üyesi, Necmettin Erbakan Üniversitesi Hemşirelik Fakültesi, Konya, Türkiye, E-mail: suserpil@gmail.com, Tel: 0-332-3204049, ORCID: 0000-0001-9263-6046 2Prof. Dr., Marmara Üniversitesi Sağlık Bilimleri Fakültesi, Hemşirelik Bölümü, İstanbul, Türkiye, E-mail: salpar@marmara.edu.tr, Tel: 0-216-3302070, ORCID: 0000-00030951-0106

Geliş Tarihi: 22 Ağustos 2019, Kabul Tarihi: 5 Ağustos 2020

*Bu çalışma, 15-18 Kasım 2016 tarihlerinde A Coruna/İspanya'da gerçekleştirilen 20. Uluslararası Hemşirelik Araştırmaları Kongresi'nde sözel bildiri olarak sunulmuştur. Atıf/Citation: Su S, Ecevit Alpar Ş. Leuven Kemoterapi Hasta Bilgi Ölçeğinin Geçerlik ve Güvenirliğinin Değerlendirilmesi. Hacettepe Üniversitesi Hemşirelik Fakültesi Dergisi 2020; 7(3): 232-239. DOI: 10.31125/hunhemsire.834093 


\section{GíRiş}

Özellikle hızlı ve kontrolsüz çoğalan hücrelere karşı seçici öldürücü etkisi olan kemoterapi tedavisi ${ }^{1,2,3}$ sadece anormal hücreyi değil aynı zamanda kemik iliği, saç ve mukoza gibi hızlı çoğalan normal hücreleri de etkileyerek hastada kanama, yorgunluk, enfeksiyon, alopesi, stomatit ve diyare gibi farklı komplikasyonların gelişmesine neden olmaktadır ${ }^{1,4,5}$. Günümüzde kemoterapi tedavilerinin büyük bir bölümünün ayaktan kemoterapi ünitelerinde veya kısa süre hastanede kalınarak uygulanmasından dolayı hastalar bu komplikasyonları evde yalnız yönetmek durumunda kalmaktadır6,7. Bu konudaki çalışmalar kanser hastalarının yetersiz semptom desteği aldığını ${ }^{8,9}$ ve semptomları ile başa çıkmak için yalnız kaldıklarını göstermektedir ${ }^{10}$. Bu nedenle kemoterapi ile ilişkili semptomları önlemede veya tedavi etmede hastaların öz bakım yönetimini sağlayabilmesi ve bu yönde teşvik edilmesi kanser bakımının önemli bir parçası haline gelmiştir $6,7,11$. Ancak kanser hastalarının semptomları kendi başlarına yönetmede birçok zorluk ve engelle karşılaştığı, bu zorluk ve engellerden birisinin de hastalara yeterli bilgi ve tavsiyenin verilmemesi olduğu belirtilmektedir ${ }^{12}$. Kemoterapi tedavisi uygulanan hastaları tedaviye hazırlamak, tedaviye katılımlarını teşvik etmek, tedaviye bağlılıklarını ve hastalıkla başa çıkma yeteneklerini artırmak amacıyla hastaların bilgilendirilmesi oldukça önemlidir ${ }^{6,13,14}$. Literatürde kemoterapi eğitimi verilen hastalarda; hasta memnuniyetinin, tedavi ve bakım önerilerine bağlıı̆ın, hastalığa bağlı semptomlar ile baş etmenin, öz-bakımın arttığı ve semptomlardan kaynaklı rahatsızlığın azaldığı belirtilmektedir ${ }^{14-21}$.

Kemoterapi tedavisi uygulanan hastaların tedavi komplikasyonları ve semptom yönetimi konusunda bilgi sahibi olmasının önemine vurgu yapılmasına ${ }^{4-7}$ rağmen ülkemizdeki sağlık kurumlarında verilen kemoterapi eğitimi istendik düzeyde değildir. Ayrıca hastaların kemoterapi bilgisini değerlendiren bir ölçme aracı bulunmamaktadır.

\section{Araştırmanın Amacı}

Bu çalışmada Leuven Kemoterapi Hasta Bilgi Ölçeği (LKHBÖ)'nin ülkemiz için geçerlik ve güvenirlik çalışmasını yapmak amaçlanmıştır.

\section{GEREÇ ve YÖNTEM}

\section{Araştırmanın Türü}

Metodolojik tipte bir araştırmadır.

\section{Araştırma Evren ve Örneklemi}

Araştırmanın evrenini Konya ilindeki iki üniversite hastanesinin Tıbbi Onkoloji Polikliniği'nde ayaktan kemoterapi tedavisi uygulanan tüm hastalar oluşturdu. Ölçek uyarlaması yapılırken gerekli olan örneklem büyüklüğünün hesaplanmasında yaygın görüş bir ölçeğin madde sayısı göz önüne alınarak madde sayısının 5-10 katı arasında vaka alınmasıdır22,23. Bu doğrultuda L-KHBÖ 20 maddeden oluştuğu için en az 200 hastaya ulaşılması hedeflendi ve çalışma en az bir kür kemoterapi tedavisi alan, aynı zamanda radyoterapi tedavisi almayan, görme ve işitme problemi olmayan, 18 yaş ve üstünde olan, okur yazar olan, genel durumu stabil olan, çalışmaya katılmaya gönüllü olan 239 hasta ile tamamlandı.

\section{Veri Toplama Araçları Hasta Bilgi Formu}

Form kişisel özellikler (yaş, cinsiyet, medeni durum, eğitim durumu, meslek, gelir düzeyi, yaşadığı yer, kiminle yaşadığı) ve hastalığa ilişkin özellikler (tanı, kür numarası, kemoterapi protokolü, sağlık sigortası, kronik hastalık, tedaviye ilişkin açıklama yapılma durumu, tedavinin etki ve yan etkilerini bilme) olmak üzere toplam 18 sorudan oluştu.

Leuven Kemoterapi Hasta Bilgi Ölçeği (L-KHBÖ)

Leuven Kemoterapi Hasta Bilgi Ölçeği (L-KHBÖ) (Leuven Questionnaire on Patient Knowledge of Chemotherapy (LPaKC)), Coolbrandt ve arkadaşları tarafından 2013 yılında kemoterapi tedavisi uygulanan hastalarının bilgisini değerlendirmek amacıyla Belçika'da geliştirilmiştir. Çoktan seçmeli ve Doğru/Yanlış soru tiplerini içeren ölçek 13 soru ve 20 maddeden oluşmaktadır. 12 madde genel kemoterapi bilgisini ve 8 madde hastanın tedavisine özgü bilgileri kapsamaktadır.

Dört faktörlü ölçekte, Faktör 1: Kemoterapi tedavisinin genel özellikleri (S1, S3, S4), Faktör 2: Tedavi ile ilgili olumsuz olaylar, tedaviye bağlı yan etkiler, komplikasyonlar ve riskler (S5a, S5c, S5d, S6, S7b, S8), Faktör 3: Bilgi kaynakları (S9a, S9b, S9c), Faktör 4: Oral kemoterapinin alınması (S10, S11, S12, S13) ile ilgili soruları kapsamaktadır.

Ölçeğin puanlandırılmasında her bir soruya verilen yanlış cevapta "0"puan, doğru cevapta "1" puan verilir. Birden fazla madde içeren soruların puanlanmasında, her bir maddeye verilen puanlar toplanıp madde sayısına bölünür ve böylece soru puanı elde edilir (Soru 5, 7 ve 9). Ölçek toplam puanı, cevap verilen soruların puanlarının toplanarak cevap verilen soru sayısına bölünmesi ve daha sonra 100 ile çarpılması ile elde edilir. Ölçekten alınan toplam puan hastanın cevabına göre 0-100 puan arasında değişir ve bireylerin ölçekten aldıkları puan arttıkça kemoterapi hakkındaki bilgileri artar.

Soru 1 ve 2'nin puanlaması yapılırken tedavi protokolü, tümör tipi ve/ya da tedavinin amacl; soru 3'ün puanlaması yapılırken tedavi protokolü ve/ya da tedavinin amacı, soru $6,10,11,12,13$ 'ün puanlaması yapılırken tedavi protokolü dikkate alınarak puan verilir. Soru 9'daki 3 alt soruda "hayır" seçeneğini işaretleyen hastaların açıkladıkları cevap sağlık profesyoneli tarafından "yeterli (doğru) uygulama" olarak değerlendirilir ise 1 puan verilir ${ }^{19}$.

Ölçek, hasta ile araştırmacı tarafından ya da hastanın kendisinin doldurması ile uygulanmaktadır. Coolbrandt ve arkadaşlarının çalışmasında 0.67 bulunan ölçeğin Cronbach alfa kat sayısı ${ }^{19}$, bu araştırmada 0.86 bulundu.

\section{Dil Eşdeğerliği-Kültürel Uyarlamaya Yönelik} Uygulamalar

Dil eşdeğerliliğinin sağlanması için üç dil uzmanı tarafından Türkçe'ye çevirisi yapılan ölçeğin her iki dili anlayan ve bilen başka bir dil uzmanı tarafından Ingilizce'ye geri çevirisi yapıldı. Orjinal ölçek ile geri çevirisi yapılan ölçekteki maddeler karşılaştırıldı ve ölçeği geliştiren Coolbrandt'a gönderilerek değerlendirmesi istendi, böylece anlam bütünlüğü sağlanarak dil geçerliği tamamlandı. Uzmanlardan gelen öneriler doğrultusunda ölçek maddelerinde ifade bütünlüğü sağlandı. Ölçeğin 
düzenlenmiş son hali, Türkçe okunabilirlik ve anlaşılabilirliği açısından örnekleme dahil edilmeyen 10 hasta ile pilot uygulama yapılarak değerlendirildi.

\section{Kapsam-İçerik Geçerliğine Yönelik Uygulamalar}

Ölçeğin kapsam geçerliği için 9'u hemşire, 1'i onkoloji hekimi olmak üzere 10 öğretim üyesinden uzman görüşü alındı. Uzmanlardan maddelerin uygunluğuna göre; "1 puan= madde uygun değil, 2 puan= maddenin uygun şekilde değiştirilmesi gerekiyor, 3 puan= madde uygun, ancak ufak değişiklik gerekiyor, 4 puan= madde çok uygun" olarak değerlendirme yapmaları istendi. Ölçeğin kapsam-içerik geçerliği açısından uygunluğunu belirlemede Kapsam Geçerlilik İndeksi-KGi (Content Validity Index- CVI) kullanıldı.

\section{Veri Toplama Araçlarının Uygulanması}

Mart-Temmuz 2014 tarihleri arasında yapılan araştırmanın verileri ayaktan kemoterapi ünitesine gelen hastalardan aydınlatılmış onam alındıktan sonra yüz yüze görüşme yöntemi kullanılarak yaklaşık 15 dakikalık sürede toplandı. Ölçeğin test-tekrar test analizleri için hastalara kemoterapi ilacı verilmeden önce ön test uygulandı. Birinci uygulamaya katılan 30 hastaya kemoterapi ilacı bitiminden hemen sonra yardımcı araştırmacı tarafından son test uygulandı ${ }^{23-25}$. Ölçeğin güvenirlik analizinde, kemoterapi uygulanan hastaların kür sayıları arttıkça yaşadıkları semptom sayısı ve semptom şiddeti değişeceği için aralıklı test-tekrar test yöntemi yerine (en az 2 hafta ara) aralıksız test-tekrar test yöntemi kullanıldı22 ve sonuçları karşılaştırıldı.

\section{Verilerin Değerlendirilmesi}

Çalışmanın verileri bilgisayar ortamına aktarıldıktan sonra SPSS paket programı kullanılarak analiz edildi. Demografik özellikler ve ölçek cevapları sayı, yüzde, ortalama ve standart sapma kullanılarak değerlendirildi. Kapsam geçerliği için Kapsam Geçerlik İndeksi (KGi) kullanıldı. Yapı geçerliği doğrulayıcı faktör analizi ile iç tutarlılık Cronbach Alfa güvenirlik analizi ile ve madde toplam puan korelasyonu Sperman Korelasyon analizi ile değerlendirildi. Test-tekrar test güvenirliği için bağımlı örneklemde $t$ testi ve sınıf içi korelasyon analizi kullanıldı. İstatistiksel anlamlıık düzeyi $p<0.05$ olarak kabul edildi.

\section{Araştırmanın Etik Boyutu}

L-KHBÖ’yü geliştiren Coolbrandt ile internet üzerinden yazılı iletişim kurularak, ölçeğin Türkçeye uyarlanması için gerekli izin ve işbirliği sağlandı. Araştırmanın uygulanabilmesi için Selçuk Üniversitesi Tıp Fakültesi Girişimsel Olmayan Klinik Araştırmalar Değerlendirme Etik Kurulu'ndan onay (2013/326) ve ilgili hastanelerden yazılı izin alınmıştır. Hastalara görüşme öncesi açılama yapılarak sözlü ve Bilgilendirilmiş Onam Formu kullanılarak yazılı izinleri alındı.

\section{Araştırmanın Sınırlılıkları}

Sonuçlarımızın araştırma örneklemi ile sınırlı olması, örneklemde oral kemoterapi tedavisi alan hasta sayısının az olması araştırmanın sınırlılıklarıdır.

\section{BULGULAR}

Araştırmaya katılan hastaların \%56.1'inin kadın, \%61.9'unun ilkokul mezunu, \%84.1'inin evli, \%71.5'inin çalıştığı, \%46.4'ünün eşi ve çocukları ile birlikte yaşadığı, \%52.7'sinin ilde yaşadığı, \%75.3'ünün ekonomik durumunun orta düzeyde olduğu, yaş ortalamalarının $54.56 \pm 12.50$ yıl ve kür sayılarının ortalama $4.18 \pm 2.33$ olduğu görüldü.

\section{Geçerlik ile İlgili Bulgular}

\section{Kapsam-içerik Geçerliği}

Ölçeğin kapsam geçerlilik indeksi (CVI) \%100 olarak bulundu. Uzman görüşlerinden elde edilen veriler sınıf içi korelasyon katsayısı yöntemiyle incelendi. Ölçeğin sınıf içi korelasyon katsayısı (ICC) 0.91 bulunarak kapsam-içerik geçerliği tamamlandı.

\section{Yapı Geçerliği}

Yapı geçerliği için faktörlerin uyumunu doğrulamak amacıyla doğrulayıcı faktör analizi yapıldı. 4 faktörlü olan ölçeğin ilk 3 faktörü analize alınırken 4. Faktörü (oral kemoterapi) oluşturan soruları yalnız 9 hasta cevap vermiş olması nedeniyle örneklem az olduğu için doğrulayıcı faktör analizine alınmadı.

Doğrulayıcı faktör analizi sonucunda uyum indeksleri Kikare:151.83 $(p<0.01)$ Serbestlik Derecesi:100, RMSEA:0.047, SRMR:0.061, CFI:0.90, NNFI:0.88, GFI:0.93, AGFI:0.90 olarak bulundu. Bu ölçeğin doğrulayıcı faktör analizinde tüm maddelerinin elde edilen yükleri 0.30 ve üzerinde bulundu (Şekil 1), (Tablo 1).

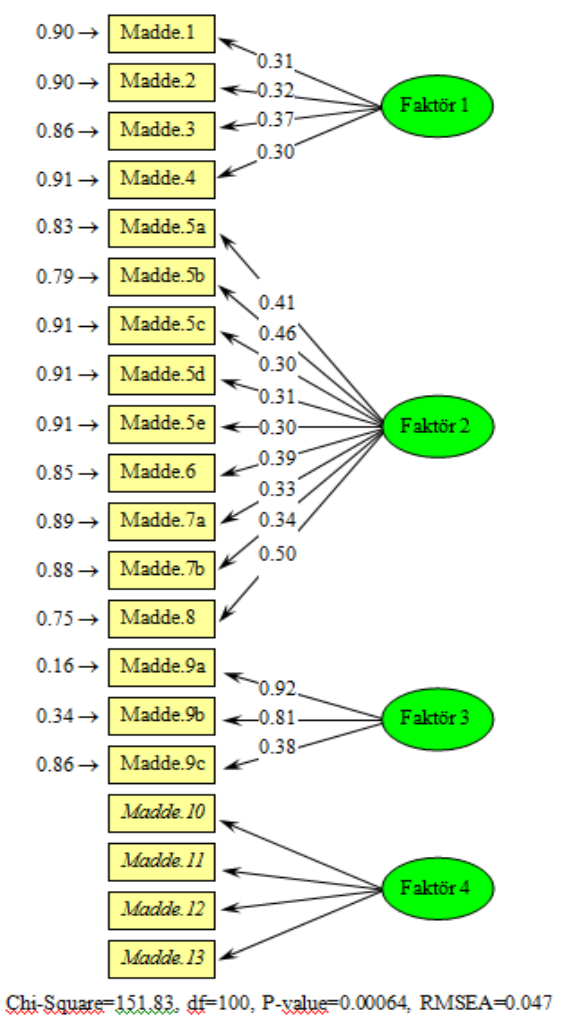

Şekil 1. Leuven Kemoterapi Hasta Bilgi Ölçeğinin Doğrulayıcı Faktör Analizi Sonuçları: Faktör Yükleri ve Hata Varyansları (Faktör 4 'de $n=9$ olduğu için analize alınmadı) 
Tablo 1. Ölçeğin Doğrulayıcı Faktör Analizi Uyumluluk Değerleri

\begin{tabular}{|c|c|c|c|}
\hline $\begin{array}{c}\text { DFA } \\
\text { Uyumluluk } \\
\text { Testleri }\end{array}$ & $\begin{array}{c}\text { Bulunan } \\
\text { DFA Sonuçları }\end{array}$ & Kabul Edilir Uyum & İyi Uyum \\
\hline $\begin{array}{l}\text { Ki-kare / p } \\
\text { değeri }\end{array}$ & $\begin{array}{c}151.83 \\
(p<0.05) \\
\end{array}$ & -- & -- \\
\hline $\begin{array}{l}\text { Serbestlik } \\
\text { Derecesi }\end{array}$ & 100 & -- & -- \\
\hline $\begin{array}{l}\text { Ki-kare değeri: } \\
\text { serbestlik } \\
\text { derecesi }\end{array}$ & $\begin{array}{c}151.83: 100 \\
1.5\end{array}$ & $2 \leq X 2 / s d \leq 5$ & $0 \leq X 2 / s d \leq 2$ \\
\hline RMSEA $(p)$ & $0.047(p<0.05)$ & $0.05 \leq \mathrm{RMSEA} \leq 0.10$ & $0 \leq \mathrm{RMSEA}<0.05$ \\
\hline SRMR & 0.061 & $0.05 \leq \mathrm{SRMR} \leq 0.10$ & $0 \leq \mathrm{SRMR} \leq 0.05$ \\
\hline $\mathrm{CFI}$ & 0.90 & $0.95 \leq \mathrm{CFI} \leq 0.97$ & $0.97 \leq \mathrm{CFI} \leq 1.00$ \\
\hline NNFI & 0.88 & $0.95 \leq \mathrm{NNFI} \leq 0.97$ & $\begin{array}{l}0.97 \leq \mathrm{NNFI} \\
\leq 1.00\end{array}$ \\
\hline GFI & 0.93 & $0.90 \leq \mathrm{GFI} \leq 0.95$ & $0.95 \leq \mathrm{GFI} \leq 1.00$ \\
\hline AGFI & 0.90 & $0.85 \leq \mathrm{AGFI} \leq 0.90$ & $\begin{array}{c}0.90 \leq \mathrm{AGFI} \\
\leq 1.00\end{array}$ \\
\hline
\end{tabular}

\section{Güvenirlik ile ilgili Bulgular iç Tutarlılık}

Maddelerin toplam puanla olan korelasyon güvenirlik katsayılarının kemoterapi tedavisinin genel özellikleri (F1), tedaviye bağlı yan etkiler (F2) ve bilgi kaynakları (F3) faktörlerinde rs:0.25 ile 0.58 arasında, pozitif yönde ve istatistiksel olarak ileri düzeyde anlamlı olduğu saptandı ( $p<0.001$, Tablo 2). Oral kemoterapinin alınması (F4) faktöründeki 10. maddenin güvenirlik katsayısının rs:0.18 olarak biraz düşük olduğu ( $p<0.01), 11 ., 12$. ve 13 . soruları az sayıda hastanın yanıtlaması (oral kemoterapi tedavisi alan hasta sayısının az olması) nedeniyle madde-toplam puan güvenirlik katsayılarının daha yüksek ve pozitif yönde olmasına karşın sadece 13. soruda anlamlı düzeyde olduğu belirlendi ( $p<0.05$, soru 12 ve 13 için $p<0.05$ ).

Maddelerin ait oldukları alt boyut toplam puanla olan korelasyon güvenirlik katsayılarının da kemoterapi tedavisinin genel özellikleri (F1), tedaviye bağlı yan etkiler (F2) ve bilgi kaynakları (F3) faktörlerinde rs:0.31 ile 0.80 arasında, pozitif yönde ve istatistiksel olarak ileri düzeyde anlamlı olduğu saptandı $(p<0.001$, Tablo 2$)$. Oral kemoterapinin alınması (F4) faktöründeki 10. maddenin kendi boyutunun toplam puanı ile güvenirlik katsayılarının ise rs:0.61-0.97 arasında olduğu, 11. ve 12. soruları az sayıda hastanın yanıtlaması nedeniyle madde-alt boyut toplam puan güvenirlik katsayılarının yüksek ve pozitif yönde olmasına karşın anlamlı düzeyde olmadığı ( $p>0.05)$, 10. ve 13. sorularda ise anlamlı düzeyde olduğu belirlendi (12 ve 13.soru için $p<0.001)$.

Ölçeğin alt boyut puanlarının toplam ölçek puanıyla ilişkisi Sperman korelasyon analizi ile incelendiğinde, güvenirlik katsayılarının rs:0.26 ile 0.85 arasında pozitif yönde ve istatistiksel olarak ileri düzeyde anlamlı olduğu bulundu ( $p<0.001$, Tablo 3).

L- KHBÖ’nin iç tutarlılık güvenirliğini gösteren Cronbach Alfa güvenirlik katsayısı 0.86 olarak saptandı. Ölçeğin alt boyutlarının Cronbach Alfa değeri kemoterapi tedavisinin genel özellikleri faktöründe daha düşük olmakla beraber, diğer üç faktörde 0.59-0.85 olarak bulundu (Tablo 3).

\section{Test-Tekrar Test Güvenirliği}

Tedavi öncesinde ve tedavi sonrasında yapılan ölçümden elde edilen hastaların L- KHBÖ puan ortalamaları arasında anlamlı düzeyde fark olmadığı (t:0.914, p:0.368), test ve tekrar test puanları arasında pozitif yönde güçlü düzeyde anlamlı bir ilişki olduğu ( $r: 0.71, p \leq 0.001)$ belirlendi (Tablo 4). Tablo 2. Leuven Kemoterapi Hasta Bilgi Ölçeğinin Madde-Toplam Puan ve Madde-Alt Boyut Toplam Puan Korelasyonları ( $n=239$ )

\begin{tabular}{|c|c|c|c|c|}
\hline \multirow[t]{2}{*}{ Bilgi Ölçeği Maddeleri } & \multicolumn{2}{|c|}{\begin{tabular}{|l|} 
Madde-Toplam \\
Korelasyonu
\end{tabular}} & \multicolumn{2}{|c|}{\begin{tabular}{|l|} 
Madde-Alt Boyu \\
Korelasyonu
\end{tabular}} \\
\hline & $r_{s}$ & $\mathbf{p}$ & $r_{s}$ & p \\
\hline \multicolumn{5}{|c|}{ 1. Faktör: Kemoterapi tedavisinin genel özellikleri } \\
\hline 1. Tedavinizin amacı nedir? & 0.41 & $\leq 0.001$ & 0.49 & $\leq 0.001$ \\
\hline $\begin{array}{l}\text { 2. Tedaviniz için planlanan } \\
\text { süre }\end{array}$ & 0.43 & $\leq 0.001$ & 0.59 & $\leq 0.001$ \\
\hline $\begin{array}{l}\text { 3. Tedaviniz verilmeden veya } \\
\text { kaydınız yenilenmeden önce, } \\
\text { yapılan kan testlerinin amacı } \\
\text { nedir? }\end{array}$ & 0.53 & $\leq 0.001$ & 0.62 & $\leq 0.001$ \\
\hline $\begin{array}{l}\text { 4. Tedaviniz sırasında hangi } \\
\text { önlemler alınmalıdır? }\end{array}$ & 0.46 & $\leq 0.001$ & 0.54 & $\leq 0.001$ \\
\hline \multicolumn{5}{|l|}{ 2. Faktör: Tedaviye bağlı yan etkiler } \\
\hline $\begin{array}{l}\text { 5a. Titreme enfeksiyon belirtisi } \\
\text { olabilir }\end{array}$ & 0.29 & $\leq 0.001$ & 0.41 & $\leq 0.001$ \\
\hline $\begin{array}{l}\text { 5b. İnatçı ishal veya inatçı } \\
\text { kusma, bir sonraki gün vücutta } \\
\text { su eksikliğine yol açabilir. }\end{array}$ & 0.35 & $\leq 0.001$ & 0.34 & $\leq 0.001$ \\
\hline $\begin{array}{l}\text { 5c. Tedavi sırasında ani nefes } \\
\text { darlığı yaşarsanız, biraz daha } \\
\text { fazla dinlenmeniz yeterlidir. }\end{array}$ & 0.25 & $\leq 0.001$ & 0.31 & $\leq 0.001$ \\
\hline $\begin{array}{l}\text { 5d. Kemoterapi sırasındaki } \\
\text { enfeksiyonlar çoğunlukla } \\
\text { antibiyotikler ile acil tedavi } \\
\text { gerektirir. }\end{array}$ & 0.27 & $\leq 0.001$ & 0.32 & $\leq 0.001$ \\
\hline $\begin{array}{l}\text { 5e.Kemoterapiden sonra kateter } \\
\text { çevresindeki derinin kırmızı ve } \\
\text { şişmiş görünmesi normaldir. }\end{array}$ & 0.26 & $\leq 0.001$ & 0.35 & $\leq 0.001$ \\
\hline $\begin{array}{l}\text { 6. Tedaviniz sırasında hangi yan } \\
\text { etkiler ortaya çıkabilir? }\end{array}$ & 0.35 & $\leq 0.001$ & 0.41 & $\leq 0.001$ \\
\hline $\begin{array}{l}\text { 7a. Tedavinin neden olduğu } \\
\text { bulantı, genellikle ilacın } \\
\text { verilmesinden sonraki ilk } 7 \\
\text { günden fazla uzun sürmez. }\end{array}$ & 0.36 & $\leq 0.001$ & 0.43 & $\leq 0.001$ \\
\hline $\begin{array}{l}\text { 7b. Yorgunluk, tedavi bittikten } \\
\text { hemen sonra kaybolur. }\end{array}$ & 0.37 & $\leq 0.001$ & 0.53 & $\leq 0.001$ \\
\hline $\begin{array}{l}8 \text { Sizin veya eşinizin tedavi } \\
\text { sırasında gebe kalmaması neden } \\
\text { önemlidir? }\end{array}$ & 0.58 & $\leq 0.001$ & 0.78 & $\leq 0.001$ \\
\hline $\begin{array}{l}\text { 7a. Tedavinin neden olduğu } \\
\text { bulantı, genellikle ilacın } \\
\text { verilmesinden sonraki ilk } 7 \\
\text { günden fazla uzun sürmez. }\end{array}$ & 0.36 & $\leq 0.001$ & 0.43 & $\leq 0.001$ \\
\hline
\end{tabular}


Tablo 2. Leuven Kemoterapi Hasta Bilgi Ölçeğinin Madde-Toplam Puan ve Madde-Alt Boyut Toplam Puan Korelasyonları ( $n=239$ ) (devamı)

\begin{tabular}{|c|c|c|c|c|}
\hline \multicolumn{5}{|l|}{ 3. Faktör: Bilgi kaynakları } \\
\hline $\begin{array}{l}\text { 9a. Hemşirelik birimine nasıl } \\
\text { ulaşabileceğimi veya iletişim } \\
\text { bilgilerini nereden } \\
\text { bulabileceğimi biliyorum. }\end{array}$ & 0.25 & $\leq 0.001$ & 0.75 & $\leq 0.001$ \\
\hline $\begin{array}{l}\text { 9b. Hafta sonu doktora nasıl } \\
\text { ulaşabileceğimi veya iletişim } \\
\text { bilgilerini nereden } \\
\text { bulabileceğimi biliyorum. }\end{array}$ & 0.28 & $\leq 0.001$ & 0.75 & $\leq 0.001$ \\
\hline $\begin{array}{l}\text { 9c. Hastaneden alınan bilgi } \\
\text { broşüründe hangi bilgileri } \\
\text { bulabileceğimi biliyorum. }\end{array}$ & 0.29 & $\leq 0.001$ & 0.80 & $\leq 0.001$ \\
\hline \multicolumn{5}{|c|}{ 4. Faktör: Oral kemoterapinin alınması } \\
\hline $\begin{array}{l}\text { 10. Kemoterapi ilacını (tablet } \\
\text { ya da kapsül) ağızdan mı } \\
\text { alıyorsunuz? }\end{array}$ & 0.18 & 0.006 & 0.63 & $\leq 0.001$ \\
\hline $\begin{array}{l}11(\mathrm{n}: 9) \text {. Tablet veya kapsülü } \\
\text { nasıl almalısınız? }\end{array}$ & 0.41 & 0.272 & 0.61 & 0.080 \\
\hline $\begin{array}{l}12(\mathrm{n}: 9) \text {. Lütfen doğru cevabı } \\
\text { belirtiniz. }\end{array}$ & 0.41 & 0.272 & 0.61 & 0.080 \\
\hline $\begin{array}{l}13 \text { (n: 9). Bir dozu almayı } \\
\text { unuttuğunuzda ne yapmanız } \\
\text { gerekir? }\end{array}$ & 0.69 & 0.039 & 0.97 & $\leq 0.001$ \\
\hline
\end{tabular}

Tablo 3. Leuven Kemoterapi Hasta Bilgi Ölçeği Alt Boyutlarının Toplam Puanla Korelasyonu ve Cronbach Alfa Güvenirlik Katsayıları ( $n=239$ )

\begin{tabular}{|c|c|c|c|}
\hline \multirow[t]{2}{*}{ Ölçek ve Alt Boyutları } & \multicolumn{2}{|c|}{$\begin{array}{c}\text { Alt Boyut - Toplam Ölçek } \\
\text { Korelasyonu }\end{array}$} & \multirow{3}{*}{$\begin{array}{c}\begin{array}{c}\text { Cronbach } \\
\text { Alfa }\end{array} \\
0.86\end{array}$} \\
\hline & $r_{s}$ & $\mathbf{p}$ & \\
\hline $\begin{array}{l}\text { Leuven Kemoterapi Hasta Bilgi } \\
\text { Ölçeği (Toplam) }\end{array}$ & -- & - & \\
\hline \multicolumn{4}{|c|}{ Leuven Kemoterapi Hasta Bilgi Ölçeğinin Alt Boyutları } \\
\hline $\begin{array}{l}\text { Faktör 1: Kemoterapi tedavisinin } \\
\text { genel özellikleri }\end{array}$ & 0.80 & $\leq 0.001$ & 0.32 \\
\hline $\begin{array}{l}\text { Faktör 2: Tedaviye bağlı yan } \\
\text { etkiler }\end{array}$ & 0.75 & $\leq 0.001$ & 0.59 \\
\hline Faktör 3: Bilgi kaynakları & 0.37 & $\leq 0.001$ & 0.71 \\
\hline $\begin{array}{l}\text { Faktör 4: Oral kemoterapinin } \\
\text { alınması (n: 9) }\end{array}$ & 0.26 & $\leq 0.001$ & 0.85 \\
\hline
\end{tabular}

Tablo 4. Test-tekrar test bilgi puanlarının karşılaştırılması $(n=30)$

\begin{tabular}{|c|c|c|c|c|c|}
\hline ölçüm Zamanı & $\mathrm{X} \pm \mathrm{SS}$ & $t$ & p & $r$ & p \\
\hline Illk Toplam Puan & $6.95 \pm 2.04$ & \multirow[b]{2}{*}{0.914} & \multirow[b]{2}{*}{0.368} & \multirow[b]{2}{*}{0.71} & \multirow[b]{2}{*}{$\leq 0.001$} \\
\hline $\begin{array}{l}\text { Tekrar Test } \\
\text { Toplam Puan }\end{array}$ & $6.71 \pm 1.68$ & & & & \\
\hline
\end{tabular}

\section{TARTIŞMA}

\section{Ölçeğin Geçerlik Bulgularının Tartışılması Kapsam-içerik Geçerliğine ilişkin Bulguların Tartışması}

Kapsam geçerliği; ölçeğin, bütününün ve alt boyutlarının ölçülmek istenen alanı ölçüp ölçmediğini ve ölçülecek alan dışında farklı kavramları barındırıp barındırmadığını değerlendirmek amacıyla yapılır ${ }^{23}$. Coolbrandt ve arkadaşlarının çalışmasında ölçeğin KGi 0.78-1.00 arasında bulunmuştur. Bu çalışmada ise $\mathrm{KGI}=1.00$ olarak bulundu. Ölçeğin sınıf içi korelasyon katsayısı (SKK=ICC) 0.91 olarak bulundu. Literatüre göre sınıf içi korelasyon katsayısı kabul düzeyi $0.70^{\prime}$ dir $^{26}$. Bu değerler uyumun kabul edilebilir düzeyde olduğunu göstermektedir. Bu sonuçlar doğrultusunda L-KHBÖ'nin ölçülmek istenen alanı temsil ettiği ve kapsam geçerliğinin sağlandığı söylenebilir.

\section{Yapı Geçerliğine İlişkin Bulguların Tartışması}

Ölçek uyarlama çalışmalarında, yapı geçerliğinin incelenmesinde, ölçekteki maddelerin yapısı hakkında var olan bir hipotezi sınamak, uyarlanan ölçeğin faktör yapısını özgün ölçeğin faktör yapısı ile karşılaştırmak ve benzerlik ya da ayrılıklarını değerlendirebilmek için doğrulayıcı faktör analizinin kullanılması önerilir ${ }^{23}$. Doğrulayıcı faktör analizi, bir faktörü oluşturan maddelerin faktörle ilişkisinin yeterli olup olmadığını değerlendirmektedir22,27. Doğrulayıcı faktör analizinde uyum iyiliği istatistiklerinin de istenilen düzeyde olması gerekir. Ki-kare uyum istatistiği, bir modelin kabul edilebilir olması için ki-kare değerinin anlamlı çıkmaması beklenir, ancak uygulamada genelde anlamlı çıktığı görülür, çünkü bu değer örneklem büyüklüğüne çok duyarlıdır. Bunun yerine ki-kare değeri serbestlik derecesine bölünür ve çıkan değerin iki ya da altında olması modelin iyi bir model olduğunu, beş ya da daha altında olması modelin kabul edilebilir bir uyum iyiliğine sahip olduğunu gösterir $^{27,28}$. Bu çalışmada L-KHBÖ’nin doğrulayıcı faktör analizi sonuçlarına göre ölçek yapısının iyi bir model olduğu $\left(p<0.05, X^{2}: S D=1.5\right)$ belirlenmiştir.

Kullanılan diğer uyum iyiliği testleri RMSEA, SRMR, CFI, $\mathrm{NNFI}, \mathrm{GFI}, \mathrm{AGFI}{ }^{\prime} d \iota^{27,28}$. RMSEA'nın 0.08'e eşit ya da küçük olması ve $p$ değerinin 0.05 'den küçük olması uyumun iyi olduğunu ${ }^{27,28}, 0.10^{\prime}$ a eşit ya da küçük olması ise uyumun zayıf olduğunu gösterir ${ }^{28}$. SRMR'nin $0.10^{\prime}$ dan küçük olması ${ }^{28}, \mathrm{CFI}, \mathrm{NNFI}$ değerlerinin 0.90'a eşit ya da üstünde olması, AGFI'nin 0.80 'e eşit ya da üstünde olması uyumun olduğunu gösterir27,28. Bu çalışmada, Leuven Kemoterapi Hasta Bilgi Ölçeği'nin Türkçe formunda SRMR, CFI, GFI ve AGFI değerlerine göre uyumun iyi olduğu, ancak NNFI değerinin de sınıra çok yakın olmasıyla uyumun yeterli olduğu saptanmıştır.

\section{Ölçeğin Güvenirlik Bulguların Tartışması Iç Tutarlılık}

Madde-toplam puan korelasyonu test maddelerinden alınan puanlar ile testin toplam puanı arasındaki ilişkiyi açıklar. Madde-toplam puan korelasyonun pozitif ve yüksek olması (+1'e yaklaştıkça), maddelerin benzer davranışları örneklediğini ve testin iç tutarlılığının yüksek olduğunu gösterir ${ }^{29}$. Madde-toplam puan korelasyon katsayısının alt sınırı ile ilgili literatürde farklı değerler olmakla birlikte genellikle en alt seviye olarak 0,20 alınmakta, korelasyon katsayısı 0.30-0.40 arasında olan maddelerin "iyi", 0,40 üstünde olan maddelerin "çok iyi" düzeyde ayırt edici ve dolayısıyla güvenilir olduğu bildirilmektedir. Korelasyon katsayısı ne kadar yüksek ise, maddelerin güvenirliği o kadar iyidir/güçlüdür ${ }^{23,24}$. Bu çalışmada maddelerin toplam puanla olan korelasyon güvenirlik katsayılarının ilk 3 faktörde rs:0.25 ile 0.58 arasında, pozitif yönde ve istatistiksel olarak ileri düzeyde anlamlı olduğu saptandı $(p \leq 0.001)$. Oral kemoterapi alımı alt boyutundaki 10. maddenin güvenirlik katsayısının rs:0.18 olarak biraz düşük olduğu $(p \leq 0.001) 11$. , 
12. ve 13. soruları az sayıda hastanın yanıtlaması nedeniyle madde-toplam puan güvenirlik katsayılarının daha yüksek ve pozitif yönde olmasına karşın sadece 13 . soruda anlamlı düzeyde olduğu belirlendi ( $p<0.05$, soru 12 ve 13 için $p<0.05)$. Ölçekteki soruların tümünün çıkarılmadan alınmasının uygun olduğuna karar verilmiştir. 10. soruyu hastaların büyük çoğunluğunun biliyor olması güvenirlik katsayısının düşük çıkmasına neden olduğu, 11 ve 12 . sorularda güvenirlik katsayılarının anlamsız düzeyde bulunmasında ise örneklem sayısının az olmasının etkili olduğu görülmüştür.

Maddelerin ait oldukları alt boyut toplam puanla olan korelasyon güvenirlik katsayılarının da ilk 3 faktörde rs:0.31 ile 0.80 arasında, pozitif yönde ve istatistiksel olarak ileri düzeyde anlamlı olduğu saptandı $(p<0.001)$. Dördüncü alt boyuttaki 10. maddenin kendi boyutunun toplam puanı ile güvenirlik katsayılarının ise rs:0.61-0.97 arasında olduğu, 11 . ve 12. soruları az sayıda hastanın yanıtlaması nedeniyle madde-alt boyut toplam puan güvenirlik katsayılarının yüksek ve pozitif yönde olmasına karşın anlamlı düzeyde olmadığı ( $p>0.05), 10$. ve 13. sorularda ise anlamlı düzeyde olduğu belirlenmiştir (12 ve 13 . soru için $p<0.001$ ).

Cronbach alfa katsayısı likert tipi ölçeklerde kullanılması uygun olan bir iç tutarlılık tahmin yöntemidir. Cronbach alfa katsayısı, ölçekte yer alan maddelerin varyansları toplamının genel varyansa oranlanması ile bulunan bir ağırlıklı standart değişim ortalamasıdır. Bir ölçeğin Cronbach alfa katsayısı ne kadar yüksek olursa, o ölçüde ölçeğin aynı özelliğin ögelerini ölçen tutarlı maddelerden oluştuğu söylenir ${ }^{26}$. Cronbach alpha değerlendirmesinde çıkan sonuç $0.40^{\prime}$ dan küçük ise ölçme aracı güvenilir değil, 0.40-0.59 arası düşük güvenirlikte, 0.60-0.79 arası oldukça güvenilir, 0.80-1.00 arası ise yüksek derecede güvenilir olarak değerlendirilmektedir ${ }^{26,30}$. Coolbrandt ve arkadaşlarının çalışmasında ölçeğin Cronbach alfa kat sayısı 0.67 olarak saptanmıştır ${ }^{19}$. Bu çalışmada ise L-KHBÖ'nin iç tutarlılık güvenirliğini gösteren Cronbach alfa güvenirlik katsayısı 0.86 olarak saptandı. Ölçeğin alt boyutlarının Cronbach alfa değeri kemoterapi tedavisinin genel özellikleri alt boyutunda daha düşük olmakla beraber, diğer üç alt boyutta 0.59-0.85 olarak bulundu. Bu çalışmada Cronbach alfa kat sayıları yeterli düzeydedir ve saptanan bu değerler, ölçeğin iç tutarlığının yüksek olduğunu göstermektedir.

\section{Test-Tekrar Test (Zamana Karşı Değişmezlik)}

Test- tekrar test yöntemi, bir ölçme aracının aynı denek grubuna aynı koşullarda, önemli derecede hatırlamaları önleyecek kadar uzun, fakat ölçülecek özellikte önemli değişmeler olmasına izin vermeyecek kadar kısa bir zaman aralığında iki kez uygulanmasıdır ${ }^{22}$. Korelasyon katsayısı $(r)$ "0" ile "1" arasında değişen değerler alabilmektedir. Korelasyon ( $r$ ) kat sayısı değeri yükseldikçe, ifadenin etkililik düzeyi artmakta ve azaldıkça düşmektedir. Literatürde korelasyon katsayısının gücünün r:0.00-0.25 (Çok Zayıf), r:0.26-0.49 (Zayıf), r:0.50-0.69 (Orta), r:0.70-0.89 (Yüksek) ve r:0.90-1.00 (Çok Yüksek) olarak değerlendirilmesi gerektiği belirtilmektedir. Yeteri kadar yüksek bir korelasyon katsayısı, testten elde edilen ölçümlerin kararlılığına ve iki uygulama arasındaki zaman içinde ölçülen nitelikte fazla bir değişme olmadığına işaret eder²3,27,28,31.
L-KHBÖ’nin zamana göre değişmezliğini değerlendirmek üzere yapılan test-tekrar test puanları arasında pozitif yönde güçlü düzeyde anlamlı bir ilişki olduğu belirlendi. Elde edilen korelasyon katsayılarının ilk ve ikinci uygulama sonuçları arasındaki tutarlılı̆̆ı ölçeğin zamana göre değişmezliğinin yüksek düzeyde olduğunu gösterdi.

\section{SONUÇ ve ÖNERILER}

Sonuç olarak bu çalışmada, Leuven Kemoterapi Hasta Bilgi Ölçeği'nin Türk toplumunda kullanılabilecek geçerli ve güvenilir bir ölçek olduğu bulunmuştur. Ölçeğin kemoterapi tedavisi uygulanan hastaların bilgi düzeyini belirlemek ve verilen kemoterapi eğitiminin etkinliğini değerlendirmek amacıyla kullanılması ve daha büyük örneklem gruplarında geçerlik ve güvenirliğini test eden çalışmaların yapılması önerilmektedir.

Etik Kurul Onayı (Kurul adı, tarih ve sayı no): Selçuk Üniversitesi Tıp Fakültesi Girişimsel Olmayan Klinik Araştırmalar Değerlendirme Etik Kurulu'ndan onay alınmıştır (2013/326).

Çıkar Çatışması: Bildirilmemiştir.

Finansal Destek: Yoktur.

Katılımcı Onamı: Hastalardan bilgilendirilmiş onam alınmıştır.

\section{Yazar katkıları}

Araştırma dizaynı: SS, ŞEA

Veri toplama: SS

Literatür araştırması: SS, ŞEA

Makale yazımı: SS, ŞEA

Teşekkür: Çalışmaya katılan bütün hastalara teşekkür ederiz.

Ethics Committee Approval: Approval was obtained from the Non-Invasive Clinical Research Evaluation Ethics Committee of Selçuk University Faculty of Medicine (2013/326).

Conflict of Interest: Not reported.

Funding: None.

Exhibitor Consent: Informed consent was obtained from patients.

\section{Author contributions}

Study design: SS, ŞEA

Data collection: SS

Literature search: SS, ŞEA

Drafting manuscript: SS, ŞEA

Acknowledgement: We would like to thank all the patients who participated in the study.

\section{KAYNAKLAR}

1. Kaptan D, Dedeli, Ö. Teoriden uygulamaya temel iç hastalıkları hemşireliği, kavramlar ve kuramlar. İstanbul: İstanbul Tıp Kitabevi; 2012. Bölüm 8, Kanser ve hemşirelik bakımı; s.149-84.

2. Tortorice PV. Cancer nursing. 7th ed. Amerika: Jones and Bartlett Publishers; 2011. Chapter 15, Cytotoxic chemotherapy: Principles of therapy; p.353-85.

3. Can G. Onkoloji. Enç N, Editör. İç hastalıkları hemşireliği. İstanbul: Nobel Tıp Kitabevleri Ltd. Şti; 2014. 
4. Emiroğlu F. Kanser ve kanserli hasta bakımı. Sabuncu N, Ay AF, Editörler. Klinik beceriler sağlığın değerlendirilmesi, hasta bakım ve takibi. İstanbul: Nobel Tıp Kitabevleri Ltd. Şti; 2010.

5. Ovayolu Ö. Onkolojik sorunlar ve hemşirelik yönetimi. Ovayolu N, Ovayolu Ö, Editörler. Temel iç hastalıkları hemşireliği ve farklı boyutlarıyla kronik hastalıklar. Adana: Çukurova Nobel Tıp Kitabevi; 2016.

6. Coolbrandt A, Van den Heede K, Clemens K, Milisen $\mathrm{K}$, Laenen A, Wildiers $\mathrm{H}$., et al. The Leuven questionnaire for Patient Self-care during Chemotherapy (L-PaSC): Instrument development and psychometric evaluation. Eur J Oncol Nurs. 2013a;17:275-83.

7. Coolbrandt A, Dierckx de Casterlé B, Wildiers $H$, Aertgeerts B, Van der Elst E, van Achterberg $T$, et al. Dealing with chemotherapy-related symptoms at home:a qualitative study in adult patients with cancer. Eur J Oncol Nurs. 2016;25:79-92.

8. Henry DH, Viswanathan HN, Elkin EP, Traina S, Wade S, Cella, D. Symptoms and treatment burden associated with cancer treatment: results from a cross-sectional national survey in the U.S. Support Care Cancer. 2008;16:791-801.

9. Johnsen AT, Petersen MA, Pedersen L, Houmann LJ, Groenvold M. Do advanced cancer patients in Denmark receive the help they need? A nationally representative survey of the need related to 12 frequent symptoms/problems. Psychooncology. 2013;22:1724-30.

10. Spichiger E, Rieder E, Muller-Frohlich C, Kesselring, A Fatigue in patients undergoing chemotherapy, their self-care and the role of health professionals: a qualitative study. Eur J Oncol Nurs. 2012;16:165-71.

11. Mc Corkle R, Ercolano E, Lazenby M, SchulmanGreen D, Schilling LS, Lorig $K$. et al. Selfmanagement: enabling and empowering patients living with cancer as a chronic illness. CA Cancer J Clin. 2011;61:50-62.

12. Pedersen B, Koktved DP, Nielsen LL. Living with side effects from cancer treatment-a challenge to target information. Scand J Caring Sci. 2012;27:715-23.

13. Van der Meulen N, Jansen J, van Dulmen S, Bensing, J, van Wert J. Interventions to improve recall of medical information in cancer patients: a systematic review of the literature. Psychooncology. 2008;17(9):857-68.

14. Prutipinyo C, Maikeow K, Sirichotiratana N. Selfcare behaviours of chemotherapy patients. J Med Assoc Thai. 2012;95(6):30-37.

15. Williams $S$, Schreier A. The role of education in managing fatigue, anxiety, and sleep disorders in women undergoing chemotherapy for breast cancer. Appl Nurs Res. 2005;18:138-47.

16. Hack TF, Degner LF, Parker PA. The communication goals and needs of cancer patients: a review. Psychooncology. 2005;14(10):831-45.

17. Akçay D, Gözüm S. Kemoterapi alan meme kanserli hastalarda, kemoterapinin yan etkilerine ilişkin verilen eğitim ve evde izlemin yaşam kalitesine etkisinin değerlendirilmesi. Meme Sağlığı Dergisi. 2012;8(4):191-200.

18. Aranda S, Jefford M, Yates P, Gough K, Seymour J, Francis $P$. et al. Impact of a novel nurse-led prechemotherapy education intervention (ChemoEd) on patient distress, symptom burden, and treatment-related information and support needs: results from a randomised, controlled trial. An Oncol. 2012;23(1):222-31.

19. Coolbrandt A, Van den Heede K, Jans E, Laenen A, Verslype C, Wildiers $H$. et al. The Leuven Questionnaire on Patient Knowledge of Chemotherapy (L-PaKC): Instrument development and psychometric evaluation. Eur J Oncol Nurs. 2013b;17(4):465-73.

20. Reif K, de Vries U, Petermann F, Görres S. A patient education program is effective in reducing cancer-related fatigue: A multi-centre randomised two-group waiting-list controlled intervention trial. Eur J Oncol Nurs. 2013;17(2):204-13.

21. Mollaoğlu $M$, Erdoğan $G$. Effect on symptom control of structured information given to patients receiving chemotherapy. Eur J Oncol Nurs. 2014;18(1):78-84.

22. Şencan H.Sosyal ve davranışsal ölçümlerde güvenilirlik ve geçerlilik. 1. Baskı, Ankara: Seçkin Yayıncılık; 2005.

23. Gözüm S, Aksayan S. Kültürlerarası ölçek uyarlaması için rehber II: psikometrik özellikler ve kültürlerarası karşılaştırma. Hemşirelik Araştırma Geliştirme Dergisi. 2002;5(1):3-14.

24. Tavşancıl E. Tutumların ölçülmesi ve SPSS ile veri analizi. 2. Baskı. İstanbul; Nobel Yayın Dağıtım; 2005.

25. Polit DF, Beck CT. Essentials of nursing research: Appraising evidence for nursing practice. 7th ed. Philadelphia: Lippincott Williams \& Wilkins, 2010. Chapter 5, Data analysis and interpretation; p.391-572.

26. Akgül A. Tıbbi Araştırmalarda istatistiksel analiz teknikleri "SPSS uygulamaları". 3. Baskı. Ankara: Emek Ofset Ltd. Şti.; 2005.

27. Şimşek ÖF. Yapısal eşitlik modellemesine giriş temel ilkeler ve LISREL uygulamaları, Ankara: Cem web Ofset; 2007.

28. Harrington D. Confirmatory factor analysis. Newyork, USA: Oxford University Press; 2009.

29. Büyüköztürk Ş. Sosyal bilimler için veri analizi el kitabı. İstatistik, araştırma deseni, SPSS uygulamaları ve yorumu. 2. Baskı. Ankara: Pegema Yayıncılık; 2006.

30. Özdamar K. Paket programlar ile istatistiksel veri analizi. 4. Baskı. Eskişehir: Kaan Kitabevi; 2009. 
31. Erefe i. Veri toplama araçlarının niteliği. Erefe i, editör. Hemşirelikte araştırma ilke süreç ve yöntemleri. Ankara: Odak Ofset; 2002. 